\title{
Title: Sero-prevalence of bovine and human brucellosis on selected farms in South-western Uganda
}

\author{
Mary L. Nanfuka* \\ Animal Health, Ministry of Agriculture Animal Industry and Fisheries, Entebbe, Uganda
}

\section{Objective}

To determine the seroprevalence of Brucellosis antibodies in cattle in 3 districts in South-western Uganda (Mbarara, Kiruhura and Bushenyi) and to determine the seroprevalence of Brucellosis among the cattle keepers on farms with cattle detected with brucellosis antibodies in the same districts and also to determine the level of awareness of Brucellosis disease among individuals that get in contact with livestock in the same districts

\section{Introduction}

Brucellosis is among the zoonotic diseases that continue to afflict man and animals in Uganda. The increase in the number of disease outbreaks in animals from 1990 to 2013 and the number of human patients diagnosed with brucellosis in private clinics and hospitals has placed the infection to be among the top re-emerging diseases in the country. Brucellosis infection in humans is non-specific and caused by direct or indirect contact with infected animals or their products. Brucellosis manifests as intermittent fever, headache, weakness, profuse sweating, chills, weight loss, generalized aching that may involve multiple organ systems in the body. In animals, Brucella organisms localize in the reproductive organs, causing abortions, decreased milk yields and temporary sterility. Its effects impact negatively to the sale value of the affected animals causing financial losses to the animal owners.

\section{Methods}

Purposive surveys were conducted in selected farms that were in an area with reported human cases. Ethical clearances were sought. Screening for Brucellosis was done using SAT. All positive samples were subjected to i-ELISA that detects IgM immunoglobulins. A total of 1503 cattle from 113 farms were tested for Brucellosis

\section{Results}

Brucellosis test results from a total of 1503 cattle showed a seroprevalence of $14 \%$ in Kiruhura, 18\% Bushenyi and 23\% Mbarara districts respectively. ELISA-positive Brucella cases from farm attendants on the sampled farms in the same districts had a prevalence of $4 \%$ in Kiruhura, 9\% in Bushenyi and 12\% in Mbarara

\section{Conclusions}

Our findings underscore Brucella exposure as one of the major reemerging diseases that should be treated with great concern by both Ministry of Health and MAAIF. We therefore recommend that the Ministries of Health and Agriculture should increase on community sensitization on the risk of Brucella infections in humans from cattle, and promote measures that can protect high risk families from getting infected. This survey indicated that Brucellosis infections are still prevalent in Uganda and continue to occur in the local communities. The public health and animal health service providers need to work together in compiling the disease epidemiological data for a concerted disease intervention measures.

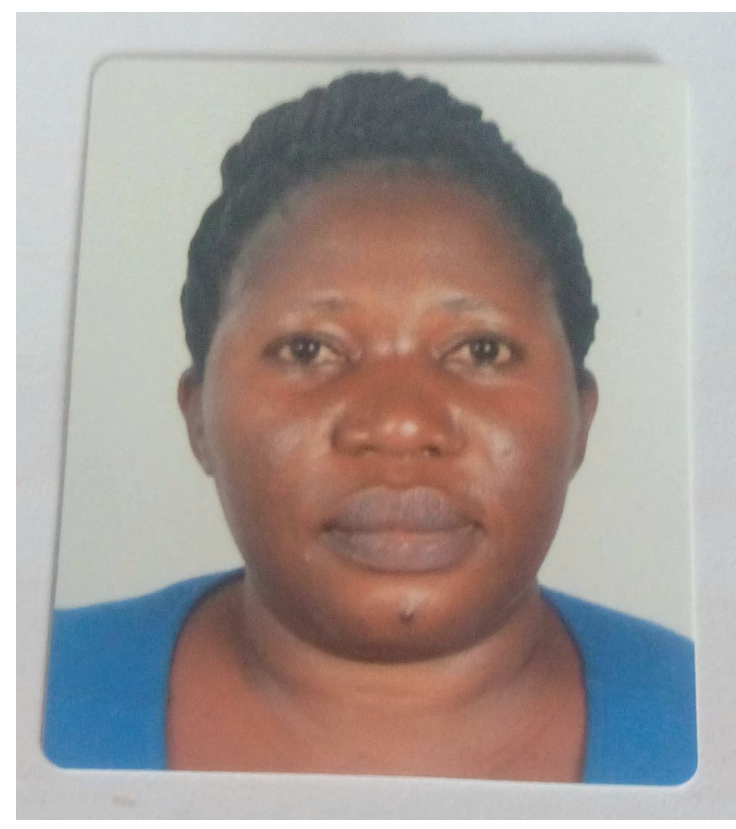

Keywords

Brucellosis; Sero prevalence; South Western Uganda

\section{Acknowledgments}

I am very grateful to the United States Department of Agriculture Biosecurity Enhancement Programme (USDA/BEP) for funding my MSc programme.

Dr Robert Tweyongyere who was a co author of this work

\section{References}

1. Al Dahouk S, Tomaso H, Nöckler K, Neubauer H, Frangoulidis D. 2003 Laboratory-based diagnosis ofbrucellosis--a review of the literature. Part II: serological tests for brucellosis. Clin Lab. 49(11):577-89.

2.Al Sekait MA. Seroepidemiological survey of brucellosis antibodies in Saudi Arabia. Ann Saudi Med 1999; 19:219-222.

3.Baba MM, Sarkindared SE, Brisibe F (2001). Serological evidence of brucellosis among predisposed patients with pyrexia of unknown origin in the north eastern Nigeria. Cent. Eur. J. Public Health. 9: 158161.161

4. Kungu, J. M., Okwee-Acai, J., Ayebazibwe, C., Okech, S. G., \& Erume, J. (2010). Sero-prevalence and risk factors for brucellosis in cattle in Gulu and Amuru districts, Northern Uganda. Africa Journal of Animal and Biomedical Sciences, 5 (3), 36-42.

5. Krause, D.O. \& Hendrick, S. (eds), 2010, Zoonotic pathogens in the food chain, CABI, Wallingford. http://dx.doi. org/10.1079/978145936815.0000

\section{*Mary L. Nanfuka}

E-mail: nanfukamry@gmail.com 